\title{
Evaluasi Konfigurasi Sambungan Baut Jembatan Rangka Baja dengan Pola Staggered Fastener (Studi Kasus: Jembatan Way Bobot, Pulau Seram)
}

\author{
EUNEKE WIDYANINGSIH, ERMA DESMALIANA, MUHAMMAD IHSAN \\ Program Studi Teknik Sipil, Institut Teknologi Nasional Bandung, Indonesia \\ Email: eunekewidya@itenas.ac.id
}

\begin{abstract}
ABSTRAK
Jembatan rangka baja merupakan tipe jembatan yang materialnya menggunakan rangka-rangka baja disambungkan oleh pelat buhul dan diikat oleh las, baut, atau gabungan dari keduanya. Jembatan rangka baja yang dianalisis merupakan Jembatan Way Bobot tipe transfield yang berada di Pulau Seram, Maluku dengan panjang bentang 60 meter. Jembatan ini dianalisis dengan menggunakan software SAP2000. Pembebanan dan perancangan jembatan mengacu pada SNI 1725:2016 dan SNI 1729:2015. Dari hasil pemodelan dan analisis pada SAP2000, dilanjutkan analisis variasi konfigurasi sambungan baut menggunakan perhitungan manual dengan metode staggered fastener. Dari hasil analisis variasi konfigurasi baut, luas penampang netto diperoleh tidak berbeda jauh sehingga dapat disimpulkan bahwa variasi konfigurasi sambungan baut sedikit berpengaruh terhadap kegagalan akibat fraktur penampang efektif netto.
\end{abstract}

Kata kunci: jembatan rangka baja, konfigurasi sambungan baut, staggered fastener

\begin{abstract}
Steel truss bridge is a type of bridge whose material uses steel frames connected by gusset plates and fastened by welding, bolts, or a combination of both. The steel truss bridge analyzed is the Transfield Way Weight Bridge located on Seram Island, Maluku with a span of 60 meters. This bridge was analyzed using SAP2000 software. The loading and design of the bridge refers to SNI 1725:2016 and SNI 1729:2015. From the results of modeling and analysis on SAP2000, continued analysis of variations in the configuration of bolted connections using manual calculations with the staggered fastener method. From the results of the analysis of variations in bolt configurations, the net cross-sectional area obtained is not much different so it can be concluded that variations in the configuration of bolted connections have little effect on failure due to fracture of the net effective cross-section.
\end{abstract}

Keywords: steel truss bridge, configuration of the bolt connection, staggered fastener 


\section{PENDAHULUAN}

Jembatan adalah struktur kontruksi yang menghubungkan dua wilayah karena adanya rintangan seperti sungai, irigasi, lembah, ataupun jalan. Jembatan berpengaruh penting terhadap ekonomi masyarakat sekitar, karena dengan adanya jembatan, mempermudah dua daerah yang terhubung untuk melakukan kegiatan.

Salah satu jenis jembatan yaitu jembatan rangka baja yang material konstruksinya terbuat dari batang-batang baja yang dihubungkan oleh sambungan berupa las, baut, atau gabungan keduanya. Semua elemen dari jembatan dihubungkan satusama lain pada titik buhul, dan menggunakan alat penyambung dinamakan pelat buhul, dan pada pelat buhul diikat oleh sambungan yang berupa las, baut, dan gabungan keduanya.

Baut merupakan salah satu alat sambung yang berbentuk batangan bulat berulir yang salah satu sisinya mempunyai kepala untuk memudahkan pemasangan saat akan dipasang mur atau pengunci baut tersebut. Pada jembatan rangka baja menggunakan baut mutu tinggi. Prinsip kerja menggunakan baut mutu tinggi pada struktur jembatan rangka baja berupa gaya jepit akibat gaya tarik baut sehingga gaya gesek antara pelat yang dijepit berfungsi sebagai penahan gaya yang bekerja.

Dalam penelitian ini dilakukan evaluasi konfigurasi sambungan baut dengan pola staggered fastener pada titik buhul jembatan rangka baja Way Bobot Pulau Seram, yang bertujuan untuk mengetahui apakah letak baut berpengaruh terhadap kapasitas penampang baja tersebut memikul beban yang diterimanya. Adapun penelitian sebelumnya yang terkait dengan penelitian ini yaitu Pramono, H.S., Sutrisno, W. \& Yasin, I. (2018) yang menganalisis displacement dan tegangan pada sambungan baut dengan menggunakan metode elemen hingga di titik buhul jembatan rangka baja. Penelitian lain yang juga terkait dengan penelitian ini yaitu Setialaksana, A.P. \& Herbudiman, B. (2017) yang mengkaji perancangan sistem sambungan struktur baja yang ekonomis dengan variasi ukuran baut, konfigurasi baut dan mutu baut pada rangka atap. Variasi ukuran baut, konfigurasi baut dan mutu baut sangat mempengaruhi kekuatan sistem sambungan baut struktur baja menjadi sangat efisien, juga sangat mempengaruhi harga material sambungan baut struktur baja menjadi sangat ekonomis.

\section{TINJAUAN PUSTAKA}

\subsection{Umum}

Jembatan merupakan peran penting bagi infrastruktur transportasi karena dalam pembangunan lebih ekonomis dibanding harus membangun infrastruktur sesuai kontur tanah yang ada. Tidak hanya untuk kendaraan, ada juga jembatan pejalan kaki (penyebrangan), jembatan rel kereta api, dan jembatan air (pipa atau saluran).

\subsection{Jembatan Rangka Baja}

Jembatan rangka baja (steel truss bridge) adalah jembatan yang dibentuk oleh berbagai batang baja yang dapat menyalurkan beban pada tiap rangkanya. Batang pada jembatan rangka terbagi menjadi batang tarik dan batang tekan. Batang tarik merupakan batang yang dibebani gaya aksial tarik yang didasarkan atas ijin tegangan tarik. Batang tekan merupakan batang yang dibebani gaya tekan aksial searah panjang bantangnya.

\subsection{Sambungan Baut (Bolt Connection)}

Baut merupakan alat sambung dari batang bulat berulir yang salah satu ujungnya dibentuk kepala baut dan ujung lainnya dipasang mur atau pengunci seperti terlihat pada Gambar 1. 
Di lapangan, sambungan baut seringkali digunakan untuk konstruksi sambungan tetap, sambungan bergerak, ataupun sambungan sementara yang dapat dilepas atau dibongkar kembali.

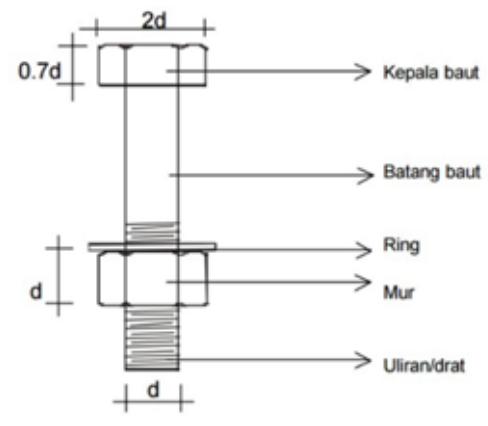

Gambar 1. Baut

Adapun keuntungan jika menggunakan sambungan baut sebagai berikut:

1. Sambungan baut mudah dipasang dan disetel di lapangan.

2. Sambungan baut dapat digunakan untuk dimensi tebal baja yang lebih dari 4 (empat) kali diameter bautnya, tidak seperti paku keling yang dimensi tebal bajanya dibatasi maksimum 4 (empat) kali diameter pakunya.

\subsection{Jenis Keruntuhan pada Sambungan Baut}

Pada suatu sistem sambungan baik baut maupun paku keling, kekuatan sambungan akan dievaluasi dengan meninjau beberapa kemungkinan keruntuhan atau kegagalan. Kekuatan sambungan biasanya dipengaruhi oleh pelat buhul dan batang yang disambung. Beberapa syarat keruntuhan sambungan antara lain:

1. Keruntuhan leleh pada penampang bruto

Keruntuhan tipe ini biasanya terjadi pada batang yang disambung seperti terlihat pada Gambar 2, dan dipengaruhi oleh luas penampang bruto batang. Perhitungan keruntuhan leleh dihitung dengan Persamaan 1.

$$
R_{n}=\phi\left(F_{y} A_{g}\right)
$$

halmana:

$\phi \quad=$ faktor keruntuhan leleh penampang bruto $(\phi=0,9)$;

$F_{y}=$ tegangan leleh baja [MPa];

$A_{g}=$ luas penampang bruto [ $\left.\mathrm{mm}^{2}\right]$.

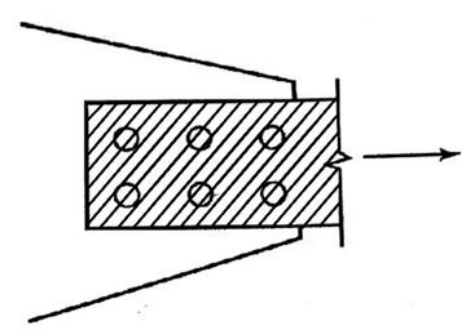

Gambar 2. Keruntuhan leleh pada penampang bruto (Sumber: Segui, W.T., 2013) 
2. Keruntuhan fraktur pada penampang efektif netto

Keruntuhan tipe ini biasanya juga terjadi pada batang yang disambung, sangat dipengaruhi oleh luas lubang baut. Apabila dimensi dan jumlah baut belum diketahui, maka luas penampang netto diasumsikan 0,8 - 0,9 luas penampang bruto. Perhitungan keruntuhan fraktur dihitung dengan Persamaan 2 yang mempertimbangkan Persamaan 3 hingga Persamaan 5.

$$
\begin{aligned}
& P_{u}=\phi\left(F_{u} A_{e}\right) \\
& A_{e}=U A_{n} \\
& A_{n}=A_{g}-n d t \\
& U=1-\frac{\bar{x}}{l}
\end{aligned}
$$

halmana:

$\phi \quad=$ faktor keruntuhan fraktur penampang efektif netto $(\phi=0,75)$;

$F_{u}=$ tegangan ultimit baja [MPa];

$A_{e}=$ luas penampang efektif netto $\left[\mathrm{mm}^{2}\right] ;$

$A_{n}=$ luas penampang netto $\left[\mathrm{mm}^{2}\right] ;$

$d=$ diameter lubang baut nominal $[\mathrm{mm}]$;

$t \quad=$ tebal batang yang ditinjau;

$U=$ faktor shear lag;

$\bar{x} \quad=$ jarak dari titik berat area tersambung ke bidang sambungan [mm];

$l=$ total jarak antar baut $[\mathrm{mm}]$.

3. Keruntuhan geser blok terhadap batang tarik dan pelat buhul

Keruntuhan tipe ini biasanya terjadi pada batang yang disambung dan pelat buhul seperti terlihat pada Gambar 3, sangat dipengaruhi oleh jarak antar baut baik horizontal maupun vertikal dan jarak ujung baut sehingga mempengaruhi luas bidang geser dan luas bidang tarik.
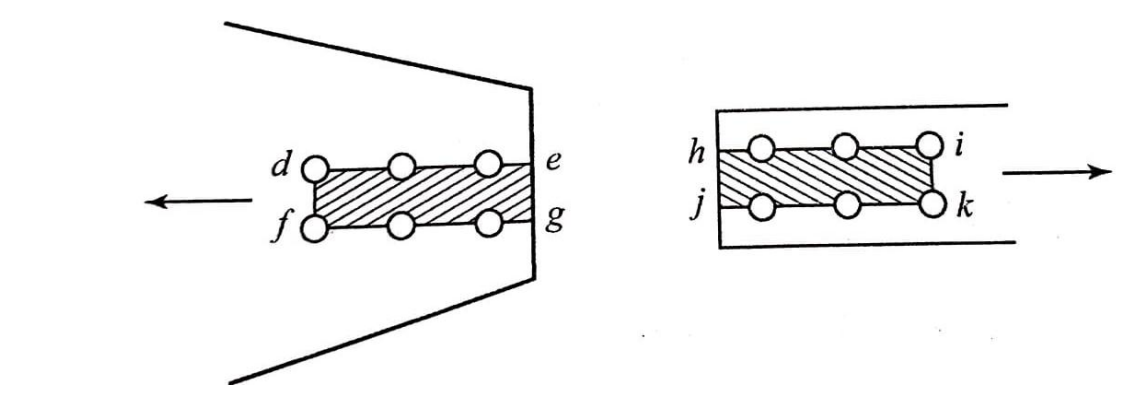

Gambar 3. Keruntuhan geser blok pada batang tarik dan pelat buhul (Sumber: Segui, W.T., 2013)

Perhitungan keruntuhan geser blok dihitung dengan Persamaan 6.

$$
P_{u}=\phi\left(0,6 F_{u} A_{n v}+U_{b s} F_{u} A_{n t}\right) \leq \phi\left(0,6 F_{y} A_{g v}+U_{b s} F_{u} A_{n t}\right)
$$

halmana:

$\phi \quad=$ faktor keruntuhan geser blok $(\phi=0,75)$;

$A_{n v}=$ luas netto sepanjang bidang geser $\left[\mathrm{mm}^{2}\right]$;

$A_{n t}=$ luas netto sepanjang bidang tarik $\left[\mathrm{mm}^{2}\right] ;$

$A_{g v}=$ luas bruto sepanjang bidang geser $\left[\mathrm{mm}^{2}\right] ;$

$U_{b s}=1,0$ (jika tegangan tarik seragam) atau 0,5 (jika tegangan tarik tidak seragam). 
4. Keruntuhan tumpu baut terhadap batang tarik dan pelat buhul

Keruntuhan tipe ini biasanya terjadi pada batang yang disambung dan pelat buhul, sangat dipengaruhi oleh jarak antar baut atau jarak ujung baut dan dimensi baut. Perhitungan keruntuhan tumpu baut dihitung dengan Persamaan 7 yang mempertimbangkan Persamaan 8 hingga Persamaan 9.

$$
P_{u}=\phi\left(1,2 l_{c} t F_{u}\right) \leq \phi\left(2,4 d_{b} t F_{u}\right)
$$

a) Baut Ujung

$$
l_{c}=l_{e}-\frac{h}{2}
$$

b) Baut Lainnya

$$
l_{c}=s-h
$$

halmana:

$\phi \quad=$ faktor keruntuhan tumpu baut $(\phi=0,75)$;

$l_{c} \quad=$ jarak tepi sampai ujung tepi baut atau jarak tepi ke tepi baut [mm],

$l_{e}=$ jarak tepi ke as lubang baut [mm],

$s=$ jarak dari as ke as antar lubang baut $[\mathrm{mm}]$,

$h=$ diameter lubang standar [mm],

$d_{b}=$ diameter baut [mm].

5. Keruntuhan geser baut

Keruntuhan tipe ini biasanya terjadi pada baut, sangat dipengaruhi oleh mutu baut dan dimensi baut. Perhitungan keruntuhan tumpu baut dihitung dengan Persamaan 10.

$$
P_{u}=\phi\left(F_{n v} A_{b} n_{s}\right)
$$

halmana:

$\phi=$ faktor keruntuhan geser baut $(\phi=0,75)$;

$F_{n v}=$ kuat geser nominal baut [MPa];

$A_{b}=$ luas penampang baut $=\pi d_{b}^{2} / 4\left[\mathrm{~mm}^{2}\right]$;

$n_{s}=$ jumlah bidang geser.

6. Keruntuhan slip kritis baut

Keruntuhan tipe ini juga biasanya terjadi pada baut, sangat dipengaruhi oleh mutu baut dan dimensi baut. Perhitungan keruntuhan slip kritis baut hanya dihitung untuk sambungan baut tipe slip dengan Persamaan 10.

$$
P_{u}=\phi\left(\mu D_{u} h_{f} T_{b} n_{s}\right)
$$

halmana:

$\phi=$ faktor keruntuhan slip kritis baut $(\phi=1,0)$;

$\mu \quad=$ koefisien slip rata-rata $(0,3$ untuk kelas $\mathrm{A})$;

$D_{u}=$ rasio rata-rata pratarik baut aktual $=1,13$;

$h_{f} \quad$ = faktor pengisi $=1$;

$T_{b} \quad=$ kuat pratarik baut $[\mathrm{kN}]$. 


\subsection{Staggered Fastener}

Pada komponen sambungan tidak selamanya baut dipasang simetris/lurus tetapi terkadang juga dipasang secara zig-zag (straggered fasteners) seperti terlihat pada Gambar 4. Penyusunan sambungan baut secara zig zag atau staggeredakan menghasilkan luasan area geser maupun tarik yang bertambah sehingga dapat meningkatkan kapasitas sambungan dengan luasan area pelat buhul yang sama dibanding dengan baut yang dipasang lurus.

Penyusunan sambungan baut dengan pola staggered memiliki banyak pilihan baik dari segi bentuk sambungan maupun jarak antar baut. Dengan jumlah baut yang sama dan luas pelat buhul yang sama, namun susunan bautnya berbeda maka akan menghasilkan kapasitas sambungan baut yang lebih besar.

Pada penelitian ini dibuat 5 variasi penyusunan sambungan baut dengan pola staggered fastener. Hal ini dilakukan dengan tujuan untuk mengakomodasi pertambahan luas bidang geser dan luas bidang tarik. Adapun Persamaan 12 dan Persamaan 13 digunakan untuk menghitung luas penampang netto dengan pola staggered.

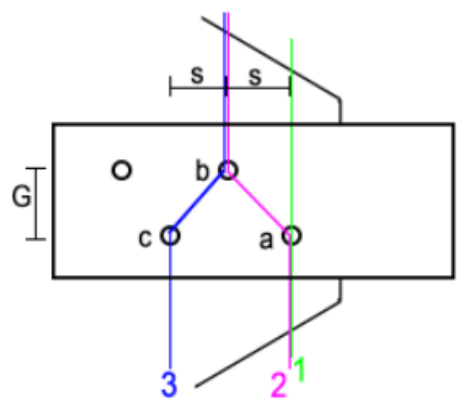

\section{Gambar 4. Pola staggered fastener}

1) Potongan a:

$$
A_{n}=A_{g}-n d t
$$

2) Potongan b-a:

$$
A_{n}=A_{g}-n d t+\sum \frac{s^{2}}{4 g} t
$$

halmana:

$g=$ jarak vertikal antar baut [mm].

\section{METODE PENELITIAN}

Penelitian ini dilakukan secara bertahap dimulai dari pemodelan jembatan rangka baja menggunakan SAP2000 untuk memperoleh nilai gaya batang maksimal yang diterima oleh rangka jembatan. Dalam tahap pemodelan ini termasuk juga perencanaan dimensi batang tarik yang memadai untuk menahan kombinasi pembebanan jembatan lalu lintas. Setelah diperoleh gaya batang maksimum, dilakukan perancangan sambungan baut di antaranya menentukan jumlah baut minimum yang diperlukan, menentukan kekuatan tumpu baut untuk mendapat tebal pelat buhul, merancang konfigurasi baut dengan konfigurasi lurus dan mengkombinasikan jumlah baut yang telah diperoleh menjadi 5 variasi konfigurasi baut secara staggered seperti terlihat pada Gambar 5 hingga Gambar $\mathbf{9}$ sehingga dapat disimpulkan variasi mana yang menghasilkan nilai luas penampang netto terbesar sehingga dapat memberikan kapasitas penampang batang dan sambungan baut yang lebih besar. 


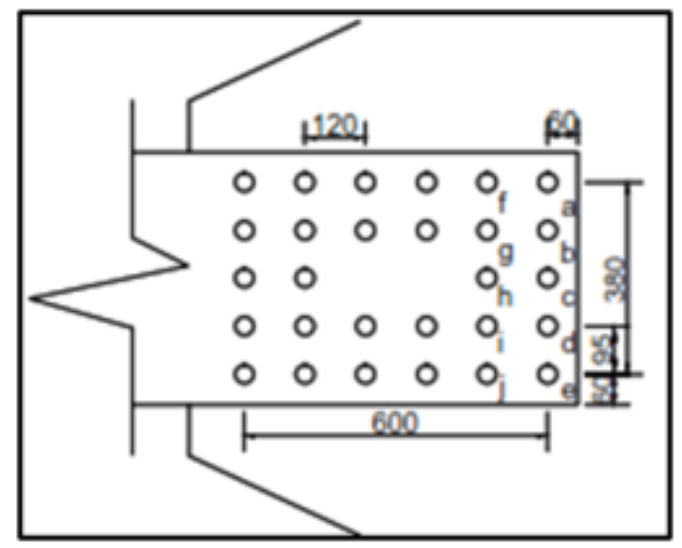

Gambar 5. Model staggered fastener 1

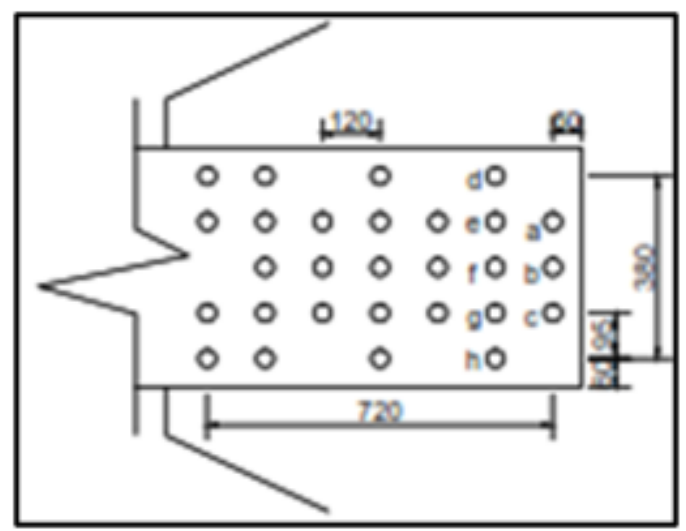

Gambar 6. Model staggered fastener 2

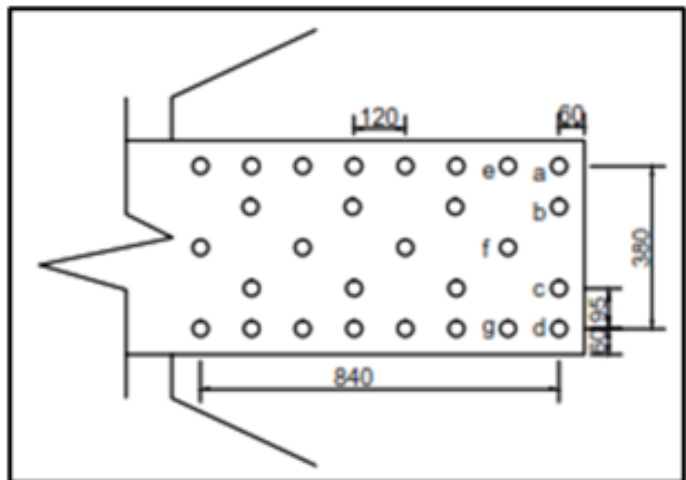

Gambar 7. Model staggered fastener 3 


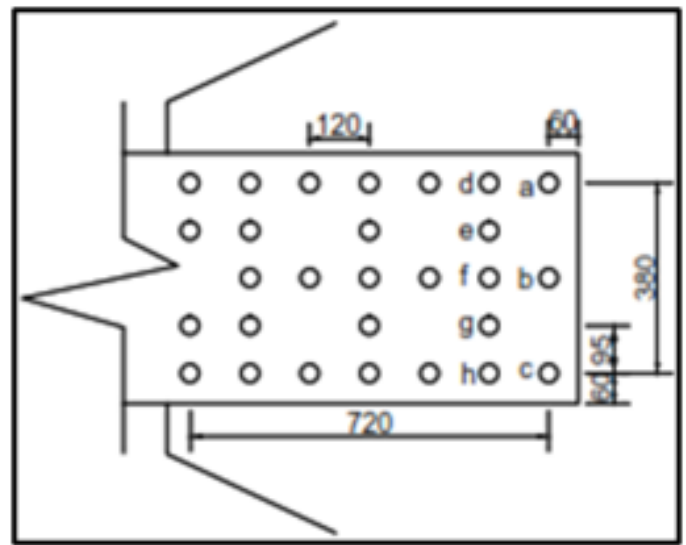

Gambar 8. Model staggered fastener 4

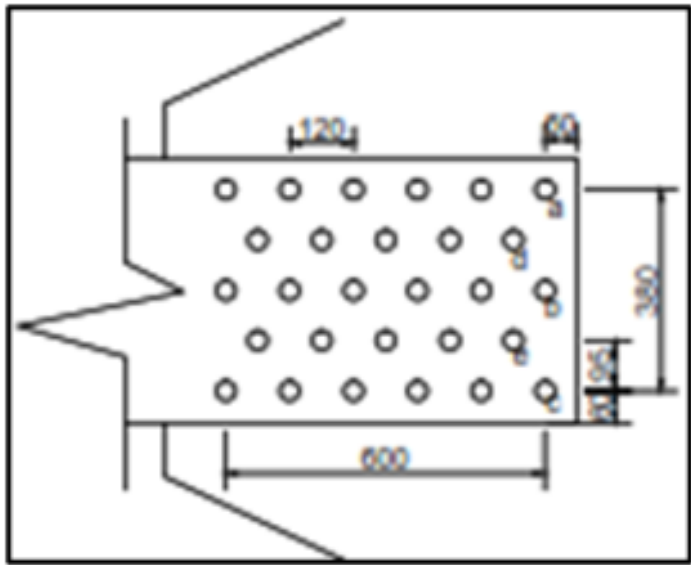

Gambar 9. Model staggered fastener 5

\section{ANALISIS DAN PEMBAHASAN}

\subsection{Pemodelan Struktur}

Struktur jembatan yang ditinjau pada penelitian ini merupakan model jembatan rangka baja. Berikut ini merupakan tampak jembatan pada Gambar 10.

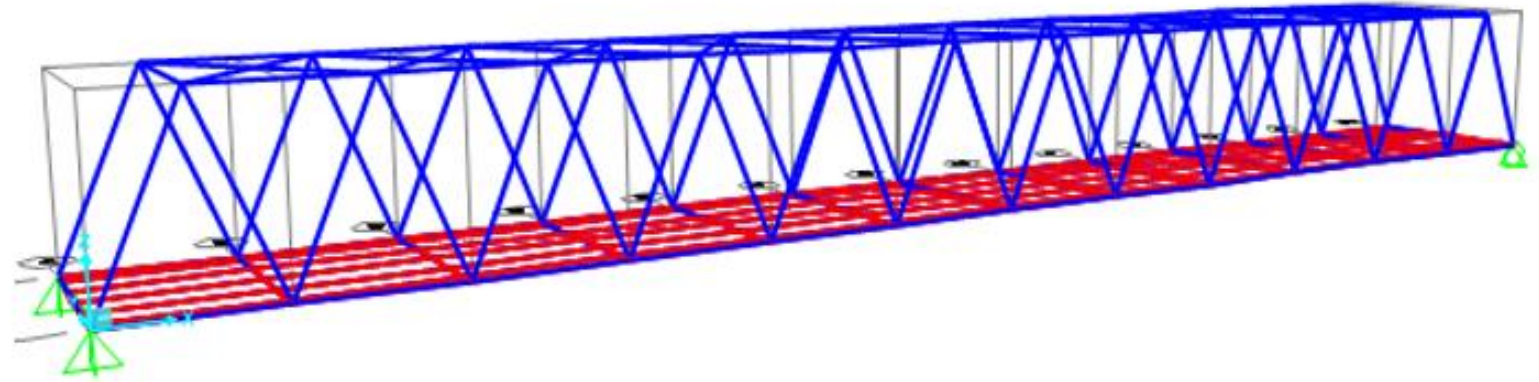

Gambar 10. Tampak 3D jembatan rangka baja

\subsection{Hasil dan Analisis Program Struktur}

Setelah preliminary pesign, dilakukan pemodelan struktur, peng-input-an beban dan kombinasi pembebanan. Selanjutnya, dilakukan analisis pada model struktur jembatan dengan cara analyze $\rightarrow$ run analysis $\rightarrow$ run now. Maka, software SAP2000 tersebut akan melakukan perhitungan analisis struktur jembatan. 
Pada software SAP2000 dari hasil analisis struktur akan diketahui diagram gaya dalam pada jembatan. Diagram gaya dalam yang ditampilkan yaitu aksial, geser atau lintang, serta momen seperti terlihat pada Gambar 11 hingga Gambar 13.

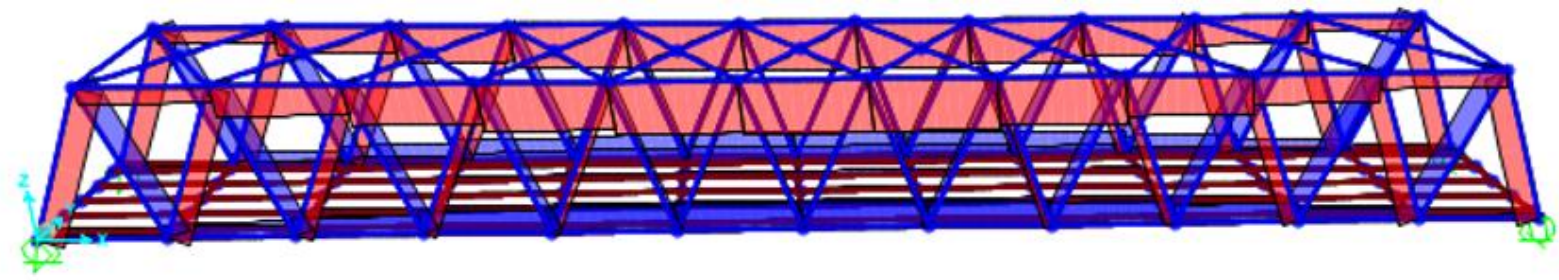

Gambar 11. Diagram gaya dalam aksial pada SAP2000

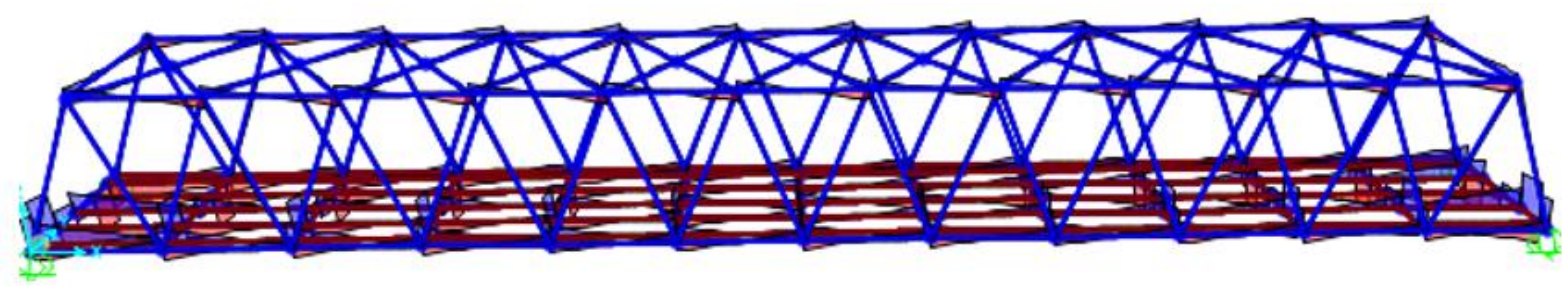

Gambar 12. Diagram gaya dalam geser pada SAP2000

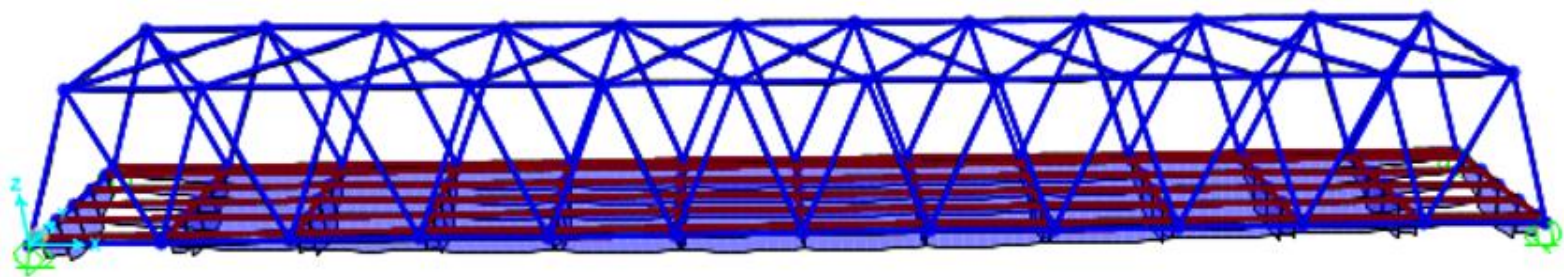

Gambar 13. Diagram gaya dalam momen pada SAP2000

Pada batang tarik didapat gaya tarik terbesar sebesar $5.426,408 \mathrm{kN}$ pada frame 314 dan pada batang tekan didapat gaya tekan terbesar sebesar $-13.487,23 \mathrm{kN}$ pada frame 214 . Berdasarkan gaya tarik dan gaya tekan terbesar didapatkan jumlah baut sebanyak 28 buah dan tebal pelat buhul sebesar $10 \mathrm{~mm}$.

\subsection{Perhitungan Staggered Fastener}

Hasil analisis luas penampang netto terhadap variasi konfigurasi sambungan baut dengan pola staggered fastener pada penelitian dapat dilihat pada Tabel $\mathbf{1}$ berikut. 
Tabel 1. Hasil Perhitungan Luas Penampang Netto dengan Staggered Fastener

\begin{tabular}{|c|c|c|c|c|c|}
\hline Tipe & $\begin{array}{c}A_{n 1} \\
{\left[\mathrm{~mm}^{2}\right]}\end{array}$ & $\begin{array}{c}A_{n 2} \\
{\left[\mathrm{~mm}^{2}\right]}\end{array}$ & $\begin{array}{c}A_{n 3} \\
{\left[\mathrm{~mm}^{2}\right]}\end{array}$ & $\begin{array}{c}A_{n 4} \\
{\left[\mathrm{~mm}^{2}\right]}\end{array}$ & $\begin{array}{c}A_{n 5} \\
{\left[\mathrm{~mm}^{2}\right]}\end{array}$ \\
\hline Potongan & $a-b-c-d-e$ & $a-b-c-d-j$ & $a-b-c-i-e$ & a-g-h-i-e & $a-g-c-i-e$ \\
\hline Model 1 & 71.800 & 76.031 & 77.603 & 83.811 & 83.852 \\
\hline Potongan & $a-b-c$ & $a-f-g-h$ & d-e-f-g-h & d-a-f-c-h & d-e-b-g-h \\
\hline Model 2 & 75.080 & 80.721 & 80.416 & 80.746 & 77.603 \\
\hline Potongan & $a-b-c-d$ & $a-b-f-c-d$ & $e-b-f-c-g$ & $a-f-d$ & $a-b-g$ \\
\hline Model 3 & 73.440 & 74.831 & 83.852 & 82.487 & 81.399 \\
\hline Potongan & $a-b-c$ & $a-e-b-g-c$ & $d-e-b-g-h$ & d-e-b-g-h & $a-f-c$ \\
\hline Model 4 & 75.080 & 77.863 & 80.587 & 80.416 & 79.432 \\
\hline Potongan & $a-b$ & c-d-e & $c-a-d-b-e$ & $a-d-b$ & a-d-e \\
\hline Model 5 & 75.080 & 85.926 & 81.400 & 78.111 & 76.031 \\
\hline
\end{tabular}

\section{KESIMPULAN DAN SARAN}

\subsection{Kesimpulan}

Setelah dilakukan pembahasan terhadap hasil analisis, maka dapat disimpulkan sebagai berikut:

1. Dari hasil run analysis SAP2000, jembatan rangka baja pada model ini mendapatkan nilai gaya tarik terbesar sebesar $5.426,408 \mathrm{kN}$ (batang nomor 34) dan nilai gaya tekan terbesar sebesar $-1.3487,2 \mathrm{kN}$ (batang nomor 214).

2. Berdasarkan hasil perhitungan sambungan baut, didapatkan jumlah baut yang paling besar pada batang tarik sebanyak 32 buah dengan diameter baut yang digunakan sebesar 36 $\mathrm{mm}$. Sementara itu, dimensi tebal pelat buhul yang didapatkan sebesar $10 \mathrm{~mm}$.

3. Berdasarkan Tabel 1, variasi baut yang menghasilkan luas penampang netto paling besar sehingga menghasilkan kapasitas maksimum yaitu model 2, 4 dan 5. Namun, sambungan baut yang paling ekonomis adalah sambungan model 1 karena memiliki dimensi pelat buhul paling kecil dibandingkan dengan model lainnya.

\subsection{Saran}

Saran untuk penelitian selanjutnya yang lebih mendalam dengan mempertimbangkan aspek-aspek lainnya, seperti:

1. Untuk analisis sambungan baut lebih mendetail, maka lebih disarankan menggunakan software khusus metode elemen hingga seperti ANSYS, ABAQUS, ataupun ADINA sehingga nilai tegangan dan regangan yang dihasilkan dapat mendekati nilai sempurna dibandingkan dengan perhitungan manual.

2. Perhitungan rancangan anggaran biaya dengan variasi sambungan baut, hal ini bertujuan untuk mendapatkan variasi sambungan baut yang ekonomis dan efisien.

\section{DAFTAR PUSTAKA}

Badan Standardisasi Nasional. (2016). SNI 1725:2016 : Pembebanan Untuk Jembatan. Jakarta: Badan Standardisasi Nasional.

Badan Standardisasi Nasional. (2015). SNI 1729-2015 : Spesifikasi Untuk Bangunan Gedung Baja Sruktural. Jakarta: Badan Standardisasi Nasional. 
Gunawan, Fauzi A S. 2012. Kajian Numerik Sambungan Balok Kolom Baja Canai Dingin. Bandung: Institut Teknologi Nasional.

Pramono, H.S. 2018. Analisis Sambungan Baut Pada Titik Buhul Jembatan Rangka Baja Menggunakan Metode Elemen Hingga. Jogjakarta: RENOVASI: Rekayasa Dan Inovasi Teknik Sipil

Segui, W.T., 2013. Steel Design $5^{\text {th }}$ Edition. USA: Cengage Learning

Setialaksana, Andre Prenata. 2017. Kajian Ekonomis Perancangan Sistem Sambungan Struktur Baja pada Rangka Atap dengan Variasi Ukuran Baut, Konfigurasi Baut, dan Mutu Baut. Bandung: Institut Teknologi Nasional. 